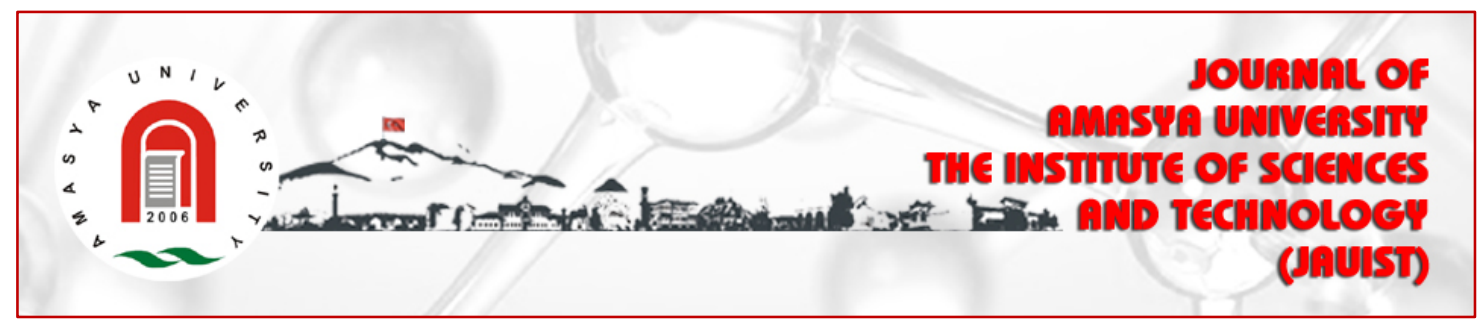

\title{
COMPARISON OF PBE AND SCAN FUNCTIONALS ON WATER-SILICA SURFACE INTERACTION
}

\section{${ }^{* 1}$ Meryem Evecen and ${ }^{* * 2,3} \mathrm{~V}$. Ongun Özçelik}

${ }^{1}$ Department of Physics, Faculty of Arts and Sciences, Amasya University, 05100, Amasya, Turkey

2Department of Natural and Mathematical Sciences, Faculty of Engineering, Ozyegin University, Cekmekoy, 34794 Istanbul, Turkey

3Department of Electrical and Computer Engineering, University of Minnesota,

Minneapolis, Minnesota 55455, USA

ORCID*: ID/0000-0001-7926-1323

ORCID**: ID/0000-0003-0645-7231

Research Type: Original Research Article

Received: 24.12.2021, Accepted: 30.12.2021

*Corresponding author: meryem.evecen@amasya.edu.tr

**Corresponding author: ongunozcelik@gmail.com

https://doi.org/10.54559/jauist.1042304

\section{Abstract}

Interaction of alpha quartz phase of silica with water is investigated the molecular level using density functional theory. First principles calculations were performed with PBE and SCAN functionals for similar binding geometries of water. It was found that water molecule binds to the 1000 surface of the alpha quartz phase from the Si atoms. Single leg orientation of water is the most favorable binding geometry of water on silica where an $\mathrm{Si}-\mathrm{H}$ bond is established on the surface. The calculations show that PBE functional gives slight over bonding values as compared to the SCAN functional.

Key Words: Silica, quartz, water, DFT. 


\section{Özet}

Silikanın alfa kuvars fazının su ile etkileşimi yoğunluk fonksiyonel teorisi ile moleküler düzeyde incelenmiştir. PBE ve SCAN fonksiyonelleri ile oluşturulan ilk prensip hesaplamalarında su molekülü Si atomları aracılığıyla alfa kuvars fazının 1000 yüzeyine bağlanmıştır. Yüzeyde Si-H bağının kurulduğu durumlarda tek bacak yöneliminin en uygun bağlama geometrisi olduğu bulunmuştur. Hesaplamalar, PBE fonksiyonelinin, SCAN fonksiyoneline göre biraz daha iyi bağlanma değerleri verdiğini göstermektedir.

Anahtar Kelimeler: Silika, kuvars, su, DFT.

Interaction of water molecule with solid surfaces has always been a topic of fundamental interest. Water-solid interaction attracts scientists from a wide range of disciplines due to the critical properties and effects that water has in a wide spectrum of fields including biology, medical science, automotive industry, solar panels, etc. [1,2]. Among the solid surfaces studied, water-silica interface is critical since it determines the surface properties of silica nanoparticles which is essential in the application of silica based devices in nanotechnology applications [3]. Water-silica interface and the adsorption of water by silica controls how silica nanoparticles accumulate or diffuse[4] around surfaces. Furthermore, the diffusion and accumulation of silica nanoparticles directly controls the adsorption of foreign molecules onto internal pores of silica based materials [5].

Computation tools provide an opportunity to investigate various effects of molecules on surfaces in a predictive way. Density function theory is particularly effective in determining the ground state interactions of isolated molecules with bulk structures at the nanoscale [6,7]. However, the results obtained from density functional theory calculations heavily depend on the type of the functional and the symmetry of the system. Therefore, it is essential to test the results of various functional at a certain test structure to provide an anchor for future computational studies. Similarly, the orientation of the molecules with respect to surfaces must be tested to find the correct orientation with minimum energy. 
To compute the binding energies of water molecule on surfaces, we performed density functional theory calculations within the generalized gradient approximation (GGA) using PBE and SCAN functionals where Van der Waals corrections [8] were included. We use projectoraugmented wave potentials and the exchange-correlation potential was approximated with PBE and SCAN functionals [9]. A vacuum spacing of $15 \AA$ in the out of plane direction was used in surface calculations. The size of the supercell is tested to avoid interactions between the water molecules of adjacent unitcells. The Brillouin zone was sampled with $15 \times 15 \times 3 \mathrm{k}$-points in the Monkhorst-Pack scheme. The convergence in energy as a function of the number of k-points was also tested for each geometry. A plane wave basis set with an energy cutoff value of $500 \mathrm{eV}$ was used. The atomic positions of the initial structures were optimized with conjugate gradient methods where the atomic forces and the total energy values were minimized. The energy convergence value between the consecutive steps was chosen as $10^{-5} \mathrm{eV}$. Numerical calculations were carried out using the VASP software [10-11]. The binding energy of the water molecule was computed by subtracting the energy of the isolated surface and water structures from the total energy of the water-silica combined system. 

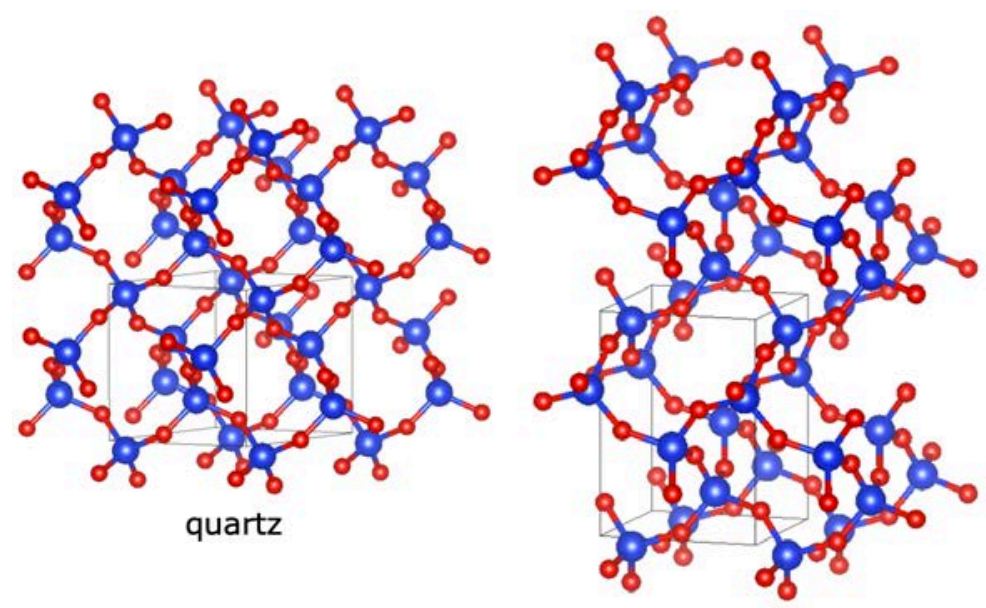

tetragonal cristobalite
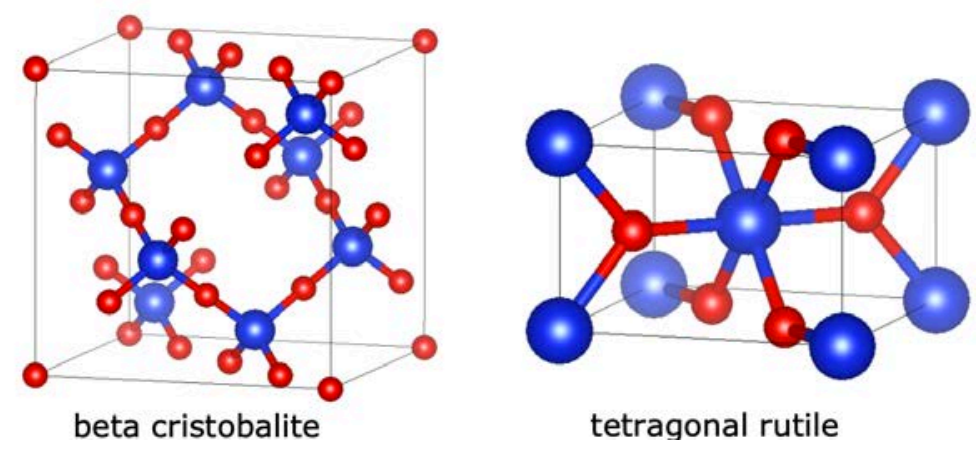

Fig. 1. Structural representations of various silica phases. In the ball-and-stick model blue and red spheres show $\mathrm{Si}$ and $\mathrm{O}$ atoms, respectively.

Silica has various stable allotropes which are alpha and beta quartz, tetragonal cristobalite, beta cristobalite, tetragonal rutile phase and the ultra thin 2D silica phases as shown in Fig. 1. Among these, alpha quartz is the most stable and the most widely used allotrope of silica. In this brief report, we present the adsorption distance of water molecule on the 1000 surface of alpha quartz using first principles calculations within DFT. Water molecule can attach to the alpha quartz surface in one of three ways: one of the $\mathrm{H}$ atoms in the water molecule can attach to the surface (one-leg orientation), both of the $\mathrm{H}$ molecules can attach to the surface (two-leg orienation), or the $\mathrm{O}$ atom in the water molecule can attach to the surface (O-bonded orientation). Here, the 0-bonded orientation is expected to be the least favorable since the 
charge carriers are located on the $\mathrm{OH}$ ends of the water molecule. Various bonding geometries of the water molecule is illustrated in Fig. 2. We first obtain the bulk form of alpha quartz and optimize its lattice parameters by minimizing the total energy of its unit cell. A surface was then cut through the 1000 direction as shown in Figure 3. Here, we use a 2x2 supercell and a vacuum size of $15 \AA$ in the out of plane direction while cutting the surface. It should be noted that it is possible to decrease the coverage of water molecules on the surface by choosing larger a supercell size.

0-leg
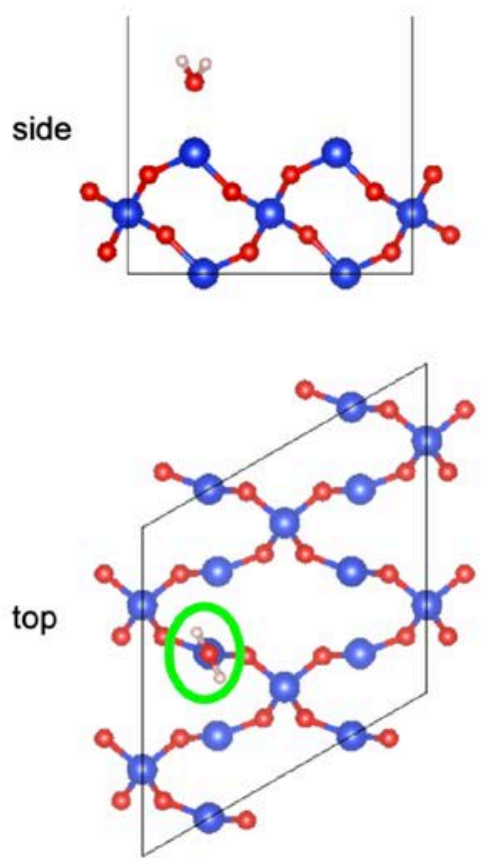

1-leg
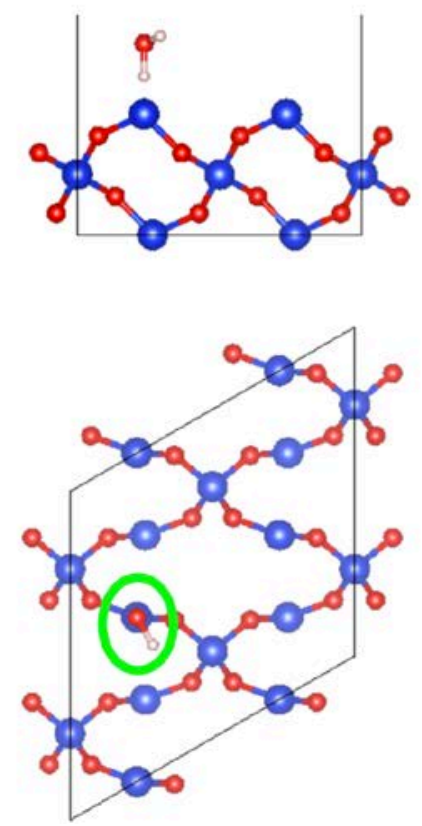

2-leg
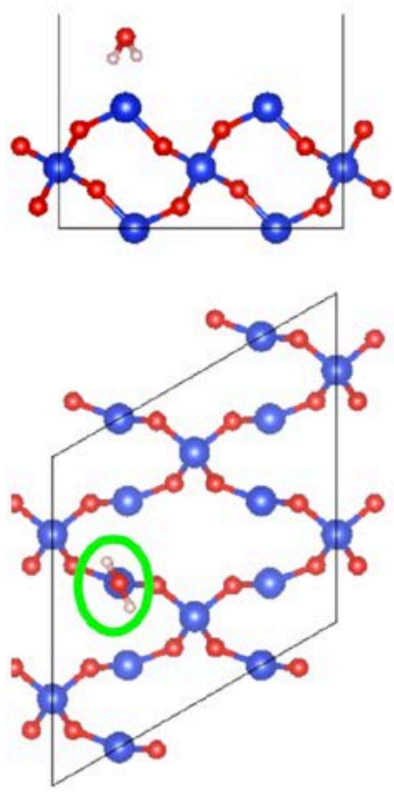

Fig. 2. Side and top views for the 0-leg, 1-leg and 2-leg binding geometries of the water molecule on alpha quartz 1000 surface. 


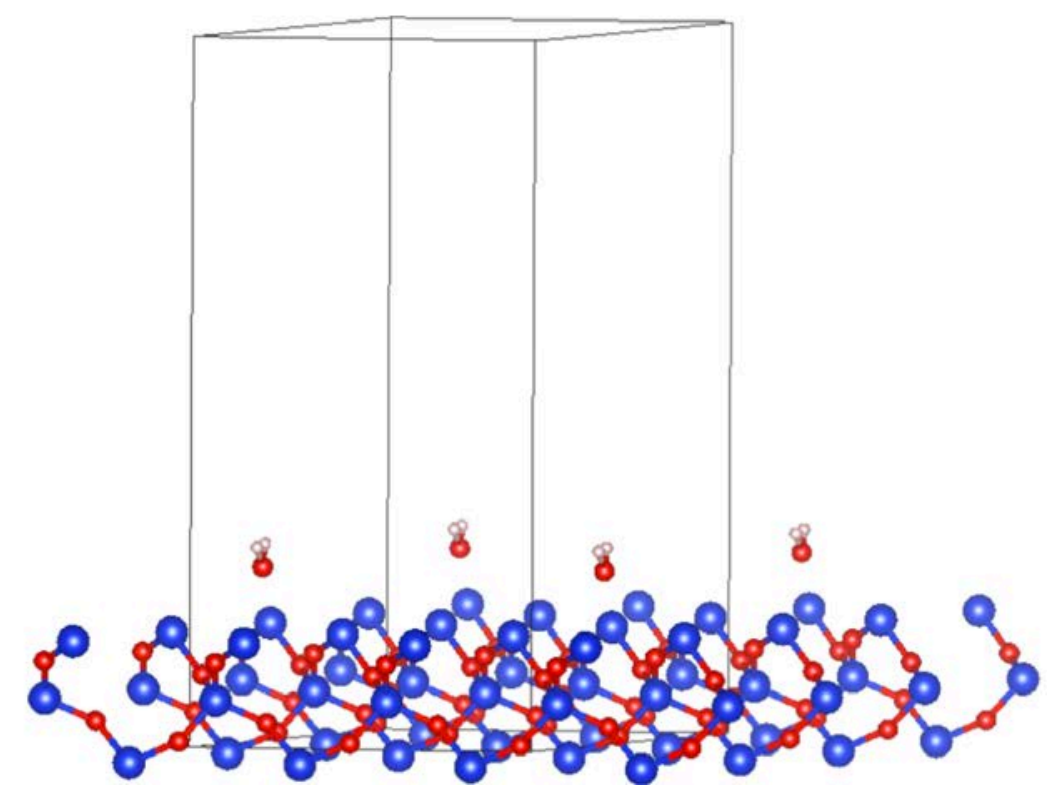

Fig. 3. Water molecules on the $2 \times 2$ supercell representation of the 1000 alpha quartz surface.

After obtaining the ground state geometry of the 1000 surface, we next place the water molecule at various distance from the surface. By keeping the molecule and the surface location fixed, we compute the total energy for each water-surface. The variation of energy as a function of water-surface distance is shown in Fig. 4. The minimum of this curve shows the ground state water-silica distance for a given geometry. The same procedure was repeated for 0-leg, 1-leg and 2-legs bonding arrangements. The energy vs distance curves for each case are computed using both the PBE functional and the SCAN functional as implemented in VASP. 


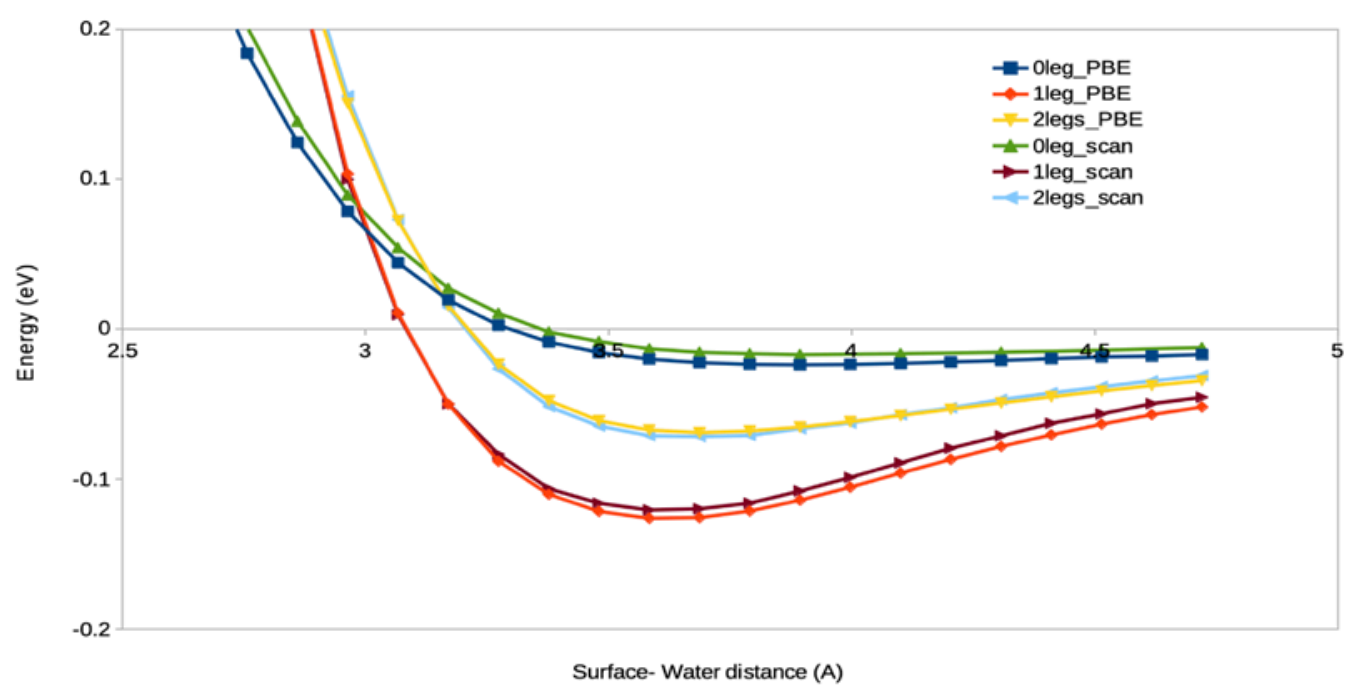

Fig. 4. Variation of the total energy of water-silica system as a function of the distance between the water molecule and the surface. Binding energies of the 0-leg, 1-leg and 2-leg water molecules are calculated with PBE and SCAN functionals.

It is seen that for both PBE and SCAN functionals, the 1-leg bonding geometry is energetically more favorable than other adsorption arrangements where the 0-leg bonding is the least favorable arrangement. PBE and SCAN functionals give similar results for the 2-legs bonding arrangement. However, for 0-leg and 1-leg structures PBE functional shows slightly over binding as compared to the SCAN functional. Therefore, considering the computation cost of performing SCAN functional calculations, PBE functional gives similar results with the SCAN functional results for obtaining the correct geometry of the water-quartz interaction. Therefore, other silica structures and other surfaces can be investigated with PBE to avoid computational difficulties. It should be noted that, hydroxilated surfaces of silica should also be investigated since cutting the bulk silica in different directions will give rise to dangling $\mathrm{OH}$ bonds. However, since the general bonding trend and arrangement of water molecule mainly depends on the orientation of the water molecule, we expect that PBE functional calculations will give similar results with the SCAN functional results on hydroxilated surfaces as well. 


\section{References}

[1] Ma, Y., Foster, A. S., \& Nieminen, R. M. (2005). Reactions and clustering of water with silica surface. The Journal of Chemical Physics, 122(14), 144709.

[2] Bouhadja, M., \& Skelton, A. A. (2018). Dynamical properties of water and ions at the quartz (101)-water interface at a range of solution conditions: A classical molecular dynamics study. The Journal of Physical Chemistry C, 122(3), 1535-1546.

[3] Chen, Y. W., Chu, I. H., Wang, Y., \& Cheng, H. P. (2011). Water thin film-silica interaction on $\alpha$-quartz (0001) surfaces. Physical Review B, 84(15), 155444.

[4] Kim, K. M., Kim, H. M., Lee, W. J., Lee, C. W., Kim, T. I., Lee, J. K., ... \& Oh, J. M. (2014). Surface treatment of silica nanoparticles for stable and charge-controlled colloidal silica. International journal of Nanomedicine, 9 (Suppl 2), 29.

[5] Rosenholm, J. M., Sahlgren, C., \& Lindén, M. (2010). Towards multifunctional, targeted drug delivery systems using mesoporous silica nanoparticles-opportunities \& challenges. Nanoscale, 2(10), 1870-1883.

[6] Ozcelik, V. O., Garg, N., White, C. E. (2019). Symmetry induced stability in alkali doped calcium-silicate-hydrate. Journal of Physical Chemistry C, 123 (22), 14081-14088.

[7] Gong, K., Ozcelik, V. O., Yang, K., White, C. E. (2021) Density functional modeling and total scattering analysis of the atomic structure of a quaternary $\mathrm{CaO}-\mathrm{MgO}-\mathrm{Al} 2 \mathrm{O} 3-\mathrm{SiO} 2$ (CMAS) glass: Uncovering the local environment of calcium and magnesium. Physical Review Materials, 5, 015603.

[8] Grimme, S. (2006). Semiempirical GGA-type density functional constructed with a longrange dispersion correction. Journal of Computational Chemistry, 27(15), 1787-1799.

[9] Perdew, J. P., Burke, K., \& Ernzerhof, M. (1996). Generalized Gradient Approximation Made Simple. Physical Review Letters, 77, 3865.

[10] Kresse, G., \& Furthmüller, J. (1996). Efficiency of ab-initio total energy calculations for metals and semiconductors using a plane-wave basis set. Computational Materials Science, 6(1), 15-50.

[11] Kresse, G., \& Furthmüller, J. (1996). Efficient iterative schemes for ab initio total-energy calculations using a plane-wave basis set. Physical Review B, 54(16), 11169. 